\title{
COMPARISION OF FLOW ANALYSIS THROUGH A DIFFERENT GEOMETRY OF FLOWMETERS USING FLUENT SOFTWARE
}

\author{
T.Sridevi ${ }^{1}$, Dhana Sekhar ${ }^{2}$, V.Subrahmanyam ${ }^{3}$ \\ ${ }^{I}$ M.Tech Scholar, Department of Mechanical Engineering, Kakinada Institute of Technology and Science, Divili, \\ Andhra Pradesh, India \\ ${ }^{2}$ Assistant Professor, Department of Mechanical Engineering, Kakinada Institute of Technology and Science, Divili, \\ Andhra Pradesh, India \\ ${ }^{3}$ Ph.D Scholar, Department of Mechanical Engineering, J.N.T.U Kakinada, Andhra Pradesh, India
}

\begin{abstract}
Flow meter or orifice meter are widely used in industry for flow measurement. A pressure loss takes place in the pipe line due to the restriction present in it. An amount of pressure loss occurs due to the thickness, shape and diameter of the plate. In the present paper, fluent software was used to plot the characteristics of the flow and gambit software was used to design the $2 D$ model. Two phase computational fluid dynamics calculations, using k-Epsilon model were employed. This simulation gives the values of pressure, velocity and turbulence contour at various sections in which water as a media. The flow analysis is done on various types of flow meters namely round plate, nozzle, short tube and borda type plates. The numerical results were validated against experimental data from the literature and were found to be good agreement.
\end{abstract}

Keywords: Gambit, Fluent, K-Epsilon model, restriction.

\section{INTRODUCTION}

Measuring the mass flow rate of a fluid running through a pipe is very important in many industries. Among the available flow metering devices, pressure differential based devices extremely applicable due to their simple design and low cost. A number of primary elements belonged to this class namely concentric orifice, eccentric orifice, wedge flow meter, venturi nozzle, and venturi meter. The selection of flow meter for given application depends upon the relative importance of measurement problems. Hence, it remains a matter of individual judgment based on engineer's knowledge and type of application. Based upon the simple principle of effect of pressure and velocity variations caused by reduction of the available area for flow in pipe. The flow meters are supplied with the discharge coefficient and the installation procedure. The discharge coefficient is defined as the ratio of actual flow to the theoretical flow. It is obtain from experimental results after regression, where in experiment are conducted in controlled condition of undistributed symmetric free velocity profile in the upstream of orifice.

Hence it is very important to understand the flow pattern of orifice meter to further improvement in its performance in terms of flow measurement with better accuracy and sensitivity.

\section{DETAILED PROCEDURE}

The current study used FLUENT, to solve the balance equation using control volume approach. These equations are solved by converting the complex partial differential equations into simple algebraic equations. The simple geometry is done in the GAMBIT software, a fine meshing is done by using successive ratio and later given the boundary conditions for the geometry and for the media. This file imported into Fluent software and has given the input values like velocity, mass flow rate, pressure, temperature etc.,

Two dimensional geometry was used to study the flow in the flow meters for solving the mass, momentum, and energy equations. The phase velocities were defined at the inlet boundary of the flow meters. The к- $\varepsilon$ turbulence models with standard wall functions were used to solve the problems. The gravitational acceleration of $9.81 \mathrm{~m} / \mathrm{s}^{2}$ in downward flow direction was used.

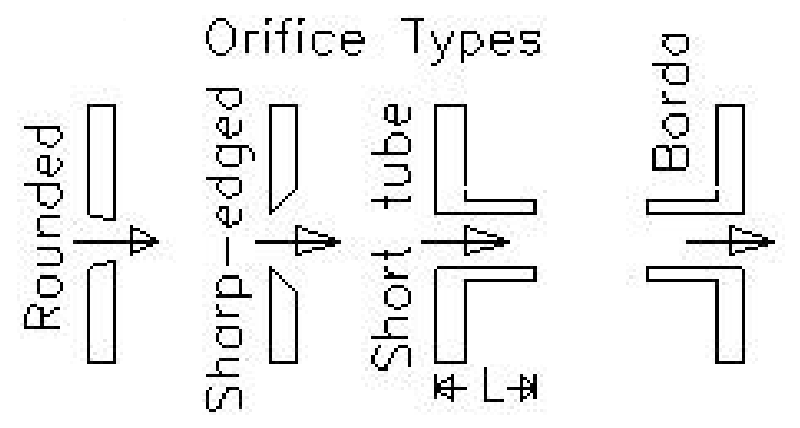

Fig-2.1: diagram of type orifice meter.

Two dimensional model is done for four different geometry namely round plate, nozzle, short tube and borda type in gambit software and simulations is done in steady state with inlet velocity of $3 \mathrm{~m} / \mathrm{sec}$ and at room temperature. Results 
are obtained for velocity, pressure and turbulence and graphs are plotted.

\section{GEOMETRY DETAILS}

The geometry was done in the GAMBIT with measurements, pipe diameter is $60 \mathrm{~mm}$, and thickness of the plate is $5 \mathrm{~mm}$ and length of the pipe $150 \mathrm{~mm}$. Defining required boundaries like inlet, outlet and wall of the geometry and mesh under tetrahedron. Defining the boundary conditions for the media as the water. The figure shows the geometry of the fluid flow through flow meters.

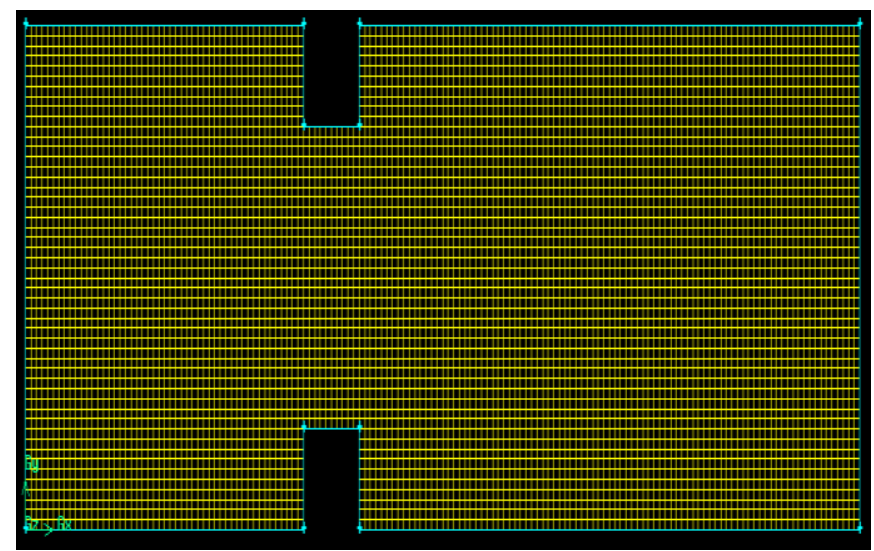

Fig- 3.1: mesh geometry of round type.

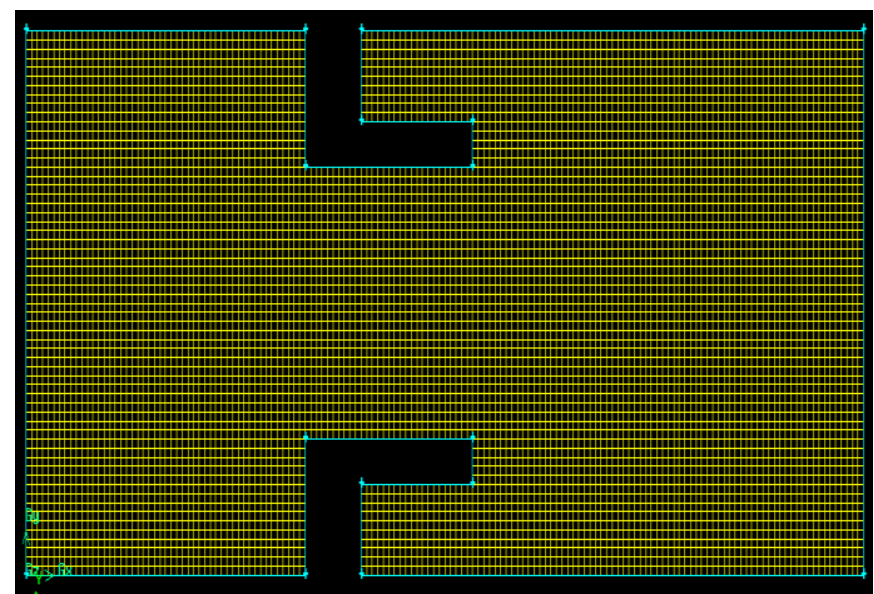

Fig- 3.2: mesh geometry of short tube.

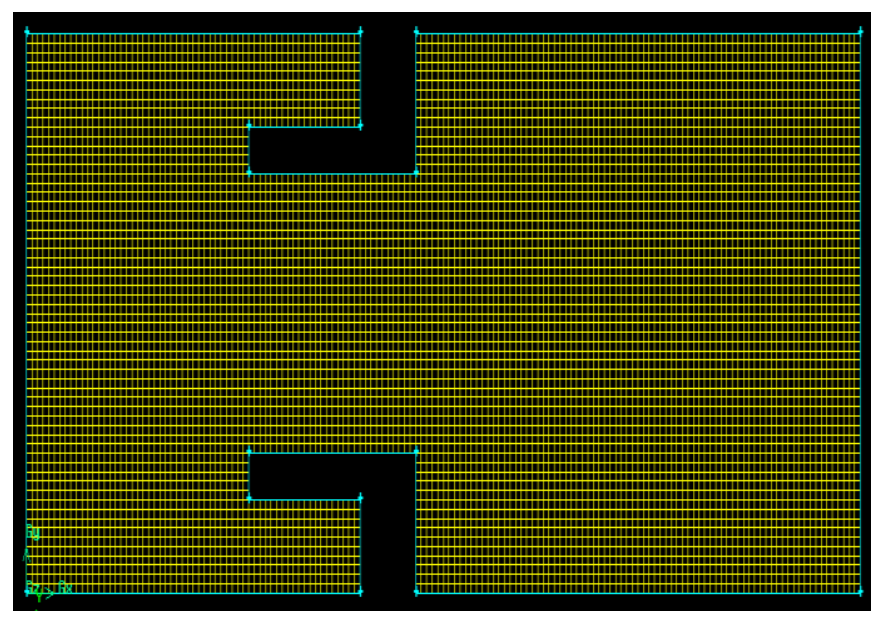

Fig- 3.3: mesh geometry of borda type.

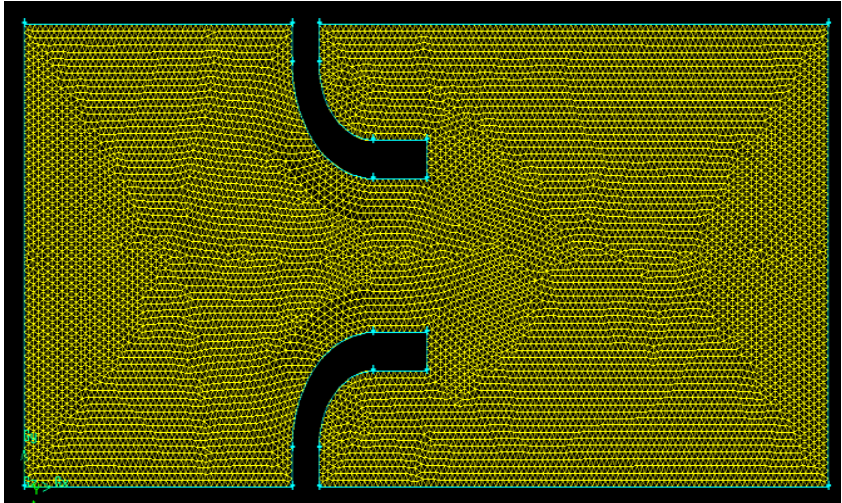

Fig- 3.4: mesh geometry of nozzle type.

\section{SOLUTION STRATEGY}

AND

\section{CONVERGENCE}

The simulation is done in the FLUENT based upon the governing equations. The steps followed in the fluent are define Model, define Material, define cell zone, boundary condition, solve, iterate, and analyze results. The governing equations used to solve this problem as below.

\subsection{Continuity Equation}

Continuity Equation also called conservation of mass. Consider fluid moves from point 1 to point 2 .

The overall mass balance is

$$
\text { Input }- \text { output }=\text { accumulation }
$$

Assuming that there is no storage,

$$
\text { Mass input }=\text { mass output. }
$$

However, as long as the flow is steady (time-invariant), within this tube, since, mass cannot be created or destroyed then the above equation.

According to continuity equation, the amount of fluid entering in certain volume leaves that volume or remains there and according to momentum equation tells about the balance of the momentum. The momentum equations are sometimes also referred as Navier-Stokes (N-S) equation. They are most commonly used mathematical equations to describe flow. The simulation is done based on the N-S equations and then K-Epsilon model.

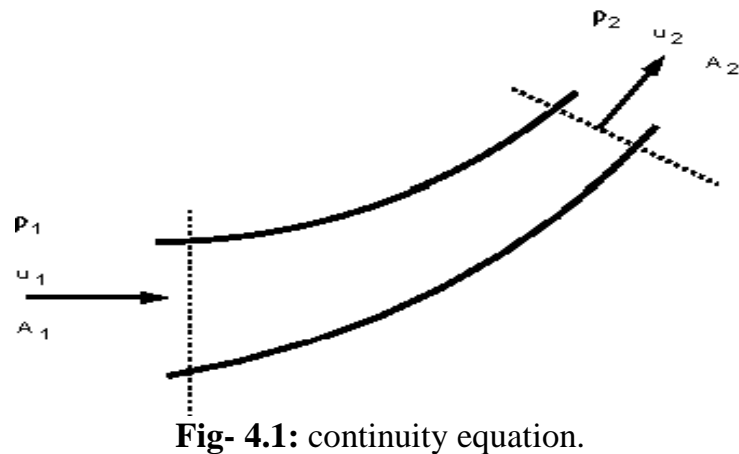




$$
\begin{aligned}
& \mathrm{m}_{1}=\mathrm{m}_{1} \\
& \frac{\mathrm{dm}_{1}}{\mathrm{dt}}=\frac{\mathrm{dm}_{1}}{\mathrm{dt}} \\
& \rho \mathrm{A}_{1} \mathrm{u}_{1}=\rho \mathrm{A}_{2} \mathrm{u}_{2} \\
& \mathrm{~A}_{1} \mathrm{v}_{1}=\mathrm{A}_{2} \mathrm{v}_{2}
\end{aligned}
$$

\subsection{Momentum Equation and Bernoulli Equation:}

It is also called equation of motion .According to Newton's 2nd law (the time rate of change of momentum of the fluid particles within this stream tube slice must equal to the forces acting on it).

$$
\mathrm{F}=\text { mass } \mathrm{x} \text { acceleration }
$$

Consider a small element of the flowing fluid as shown below, Let
dA : cross-sectional area of the fluid element,
dL : Length of the fluid element,
$\mathrm{dW}$ : Weight of the fluid element,
$\mathrm{u} \quad$ : Velocity of the fluid element,
$\mathrm{P} \quad$ : Pressure of the fluid element.

Assuming that the fluid is steady, non-viscous (the frictional losses are zero) and incompressible (the density of fluid is constant).

The forces on the cylindrical fluid element are,

1. Pressure force acting on the direction of flow (PdA).

2. Pressure force acting on the opposite direction of flow $[(\mathrm{P}+\mathrm{dP}) \mathrm{dA}]$.

3. A component of gravity force acting on the opposite direction of flow $(\mathrm{dW} \sin \theta)$.

Hence, Total force $=$ gravity force + pressure force

The pressure force in the direction of low

$$
F p=P d A-(P+d P) d A=-d P d A
$$

The gravity force in the direction of flow

$\mathrm{Fg}=-\mathrm{dW} \sin \theta\{\mathrm{W}=\mathrm{m} \mathrm{g}=\rho \mathrm{dAdL} \mathrm{g}\}$.

$=-\rho \mathrm{gdAdL} \sin \theta\{\sin \theta=\mathrm{dz} / \mathrm{dL}\}$.

$=-\rho \mathrm{gdAdz}$.

The net force in the direction of flow

$\mathrm{F}=\mathrm{m} \mathrm{a}\{\mathrm{m}=\rho \mathrm{dAdL}$.

$=\rho \mathrm{dAdL}$.

$=\rho \mathrm{dA} u \mathrm{du}$.
We have

$\rho \mathrm{dA} \mathrm{u} d u=-\mathrm{dPdA}-\rho \mathrm{g} \mathrm{dA} \mathrm{dz}\{\div \rho \mathrm{dA}\}$

$\Rightarrow \mathrm{dP} / \rho+\mathrm{udu}+\mathrm{dz} \mathrm{g}=0$--------- Euler's equation of motion.

Bernoulli's equation could be obtain by integration the Euler's equation.

$\int \mathrm{dP} / \rho+\int \mathrm{udu}+\int \mathrm{dz} \mathrm{g}=$ constant.

$\Rightarrow \mathrm{P} / \rho+\mathrm{u} 2 / 2+\mathrm{z} \mathrm{g}=$ constant.

$\Rightarrow \Delta \mathrm{P} / \rho+\Delta \mathrm{u} 2 / 2+\Delta \mathrm{zg}=0$-- Bernoulli's equation.

\subsection{Kappa-Epsilon Model}

The K-epsilon model is most commonly used to describe the behavior of turbulent flows. It was proposed by A.N Kolmogrov in 1942, then modified by Harlow and Nakayama and produced K-Epsilon model for turbulence.

The Transport Equations for K-Epsilon model are for k,

(8)

$$
\begin{aligned}
\frac{\partial}{\partial t}(\rho k)+\frac{\partial}{\partial t} & \left(\rho \mathrm{ku}_{\mathrm{i}}\right) \\
= & \frac{\partial}{\partial x_{j}}\left[\left(\mu+\frac{\mu_{\mathrm{t}}}{\sigma_{\mathrm{k}}}\right) \frac{\partial k}{\partial x_{j}}\right]+P_{k}+P_{b} \\
& -\rho \epsilon-Y_{k}+S_{k}
\end{aligned}
$$

For,

$$
\begin{aligned}
\frac{\partial}{\partial t}(\rho \epsilon)+\frac{\partial}{\partial t}( & \left(\rho \epsilon \mathrm{u}_{\mathrm{i}}\right) \\
& =\frac{\partial}{\partial x_{j}}\left[\left(\mu+\frac{\mu_{\mathrm{t}}}{\sigma_{\mathrm{k}}}\right) \frac{\partial \epsilon}{\partial x_{j}}\right] \\
& +C_{1 \epsilon} \frac{\epsilon}{k}\left(P_{k}+C_{3 \epsilon} P_{b}\right)-C_{2 \epsilon} \rho \frac{\epsilon^{2}}{k} \\
& ++S_{\epsilon}
\end{aligned}
$$

Realizable k-epsilon model and RNG k-epsilon model are some other variants of K-epsilon model. K-epsilon model has solution in some special cases. K-epsilon model is only useful in regions with turbulent, high Reynolds number flows. 


\section{RESULTS}

\subsection{Results of Round Type Flow Meter}

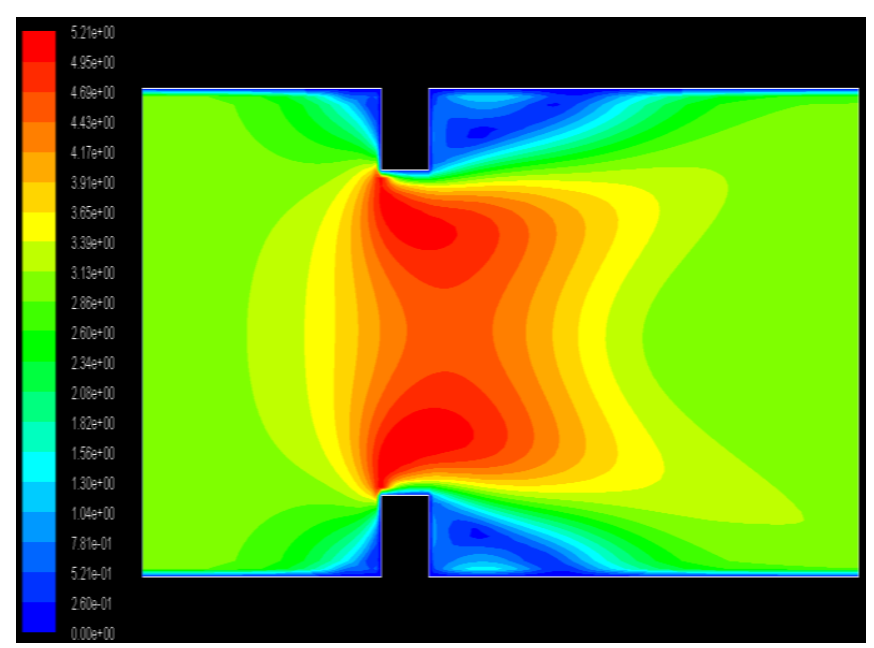

Fig- 5.1.1: velocity contours.

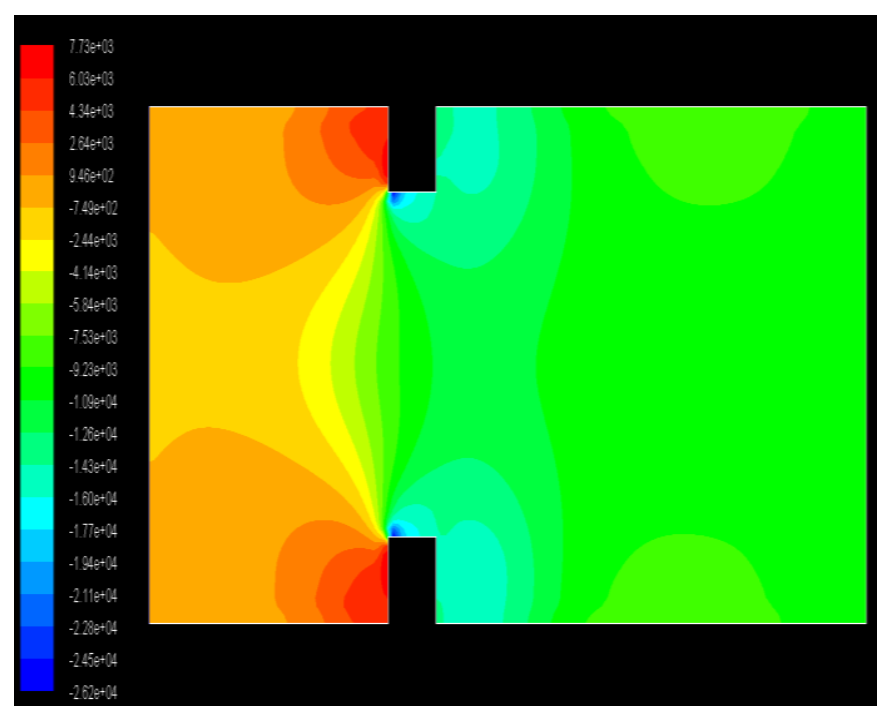

Fig- 5.1.2: pressure contours.

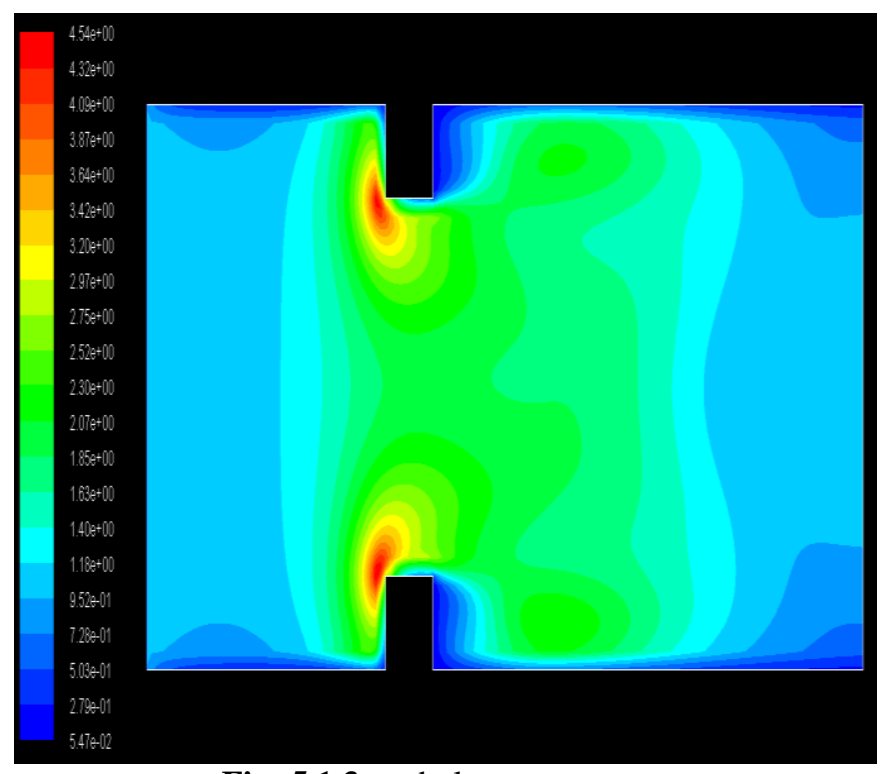

Fig- 5.1.3: turbulent contours.

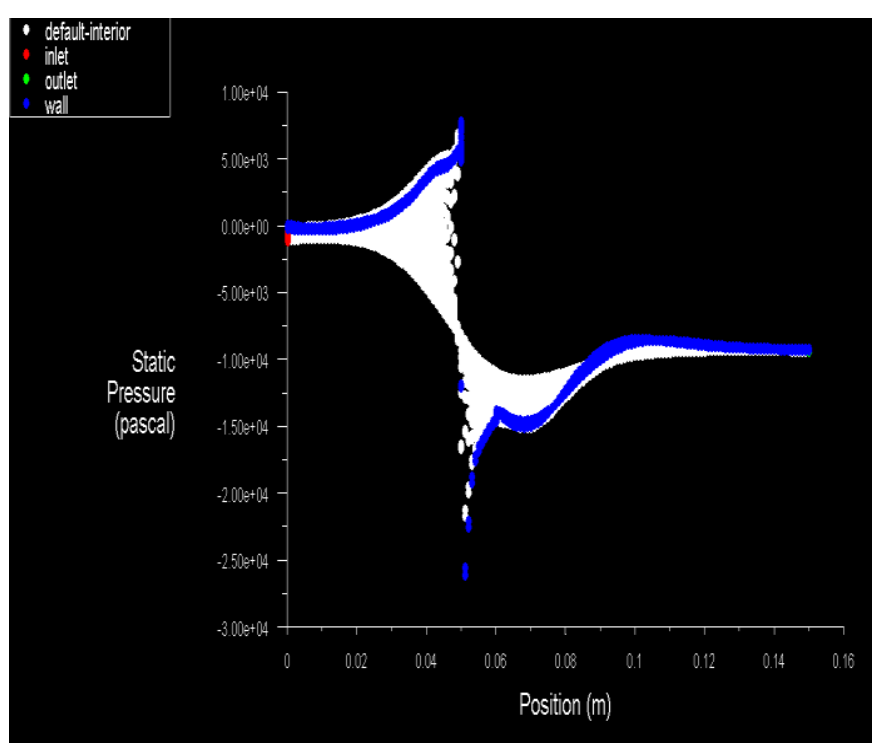

Chart-5.1.1: Pressure-position.

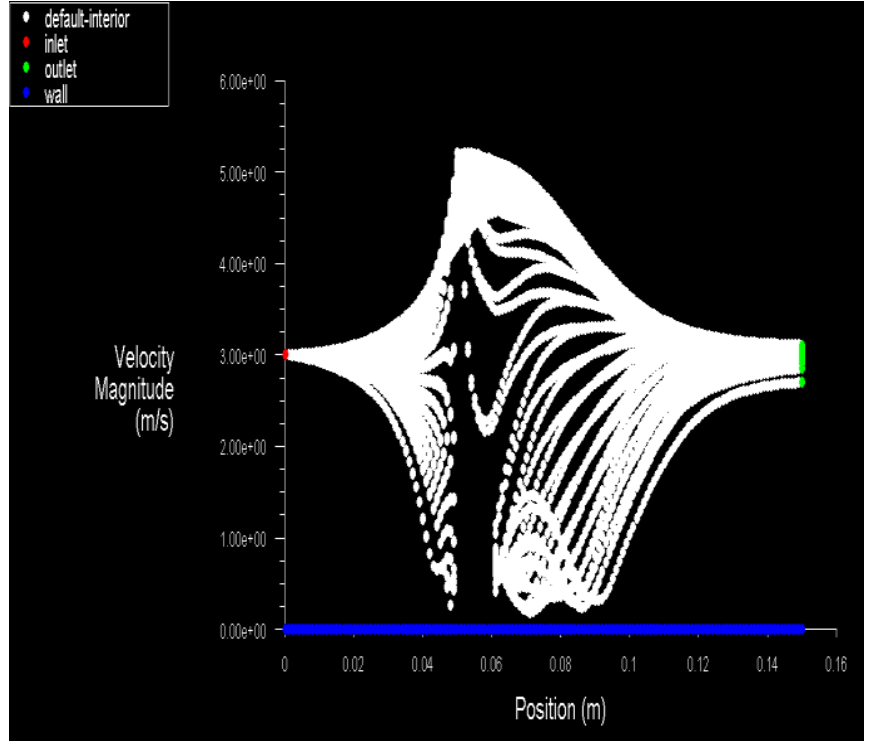

Chart-5.1.2: Velocity-position.

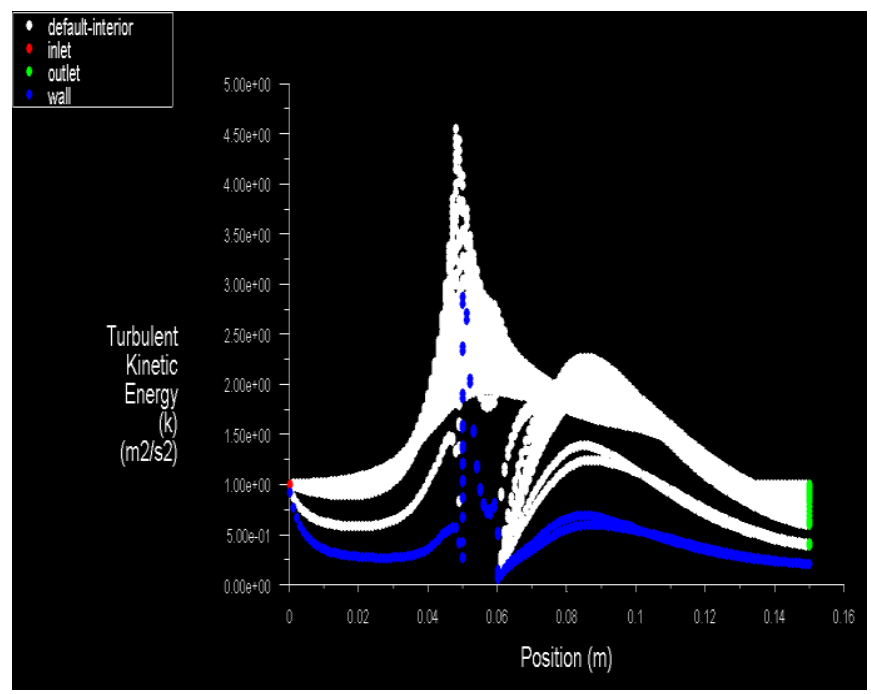

Chart-5.1.3: turbulence-position. 
Table-5.1.1: results of flow analysis.

\begin{tabular}{|c|c|c|c|}
\hline S.no & parameters & Min. & Max. \\
\hline 1 & Pressure $($ Pascal $)$ & -26180.56 & 7727.657 \\
\hline 2 & Velocity $(\mathrm{m} / \mathrm{s})$ & 0 & 5.208365 \\
\hline 3 & Turbulent $\left(\mathrm{m}^{2} / \mathrm{s}^{2}\right)$ & 0.054719 & 4.5418 \\
\hline
\end{tabular}

Table-5.1.2: results of mass flow rate.

\begin{tabular}{|c|c|}
\hline Mass Flow Rate & $(\mathbf{k g} / \mathbf{s})$ \\
\hline Interior & -5569.2096 \\
\hline Inlet & 179.67601 \\
\hline Outlet & -179.67601 \\
\hline Wall & 0 \\
\hline
\end{tabular}

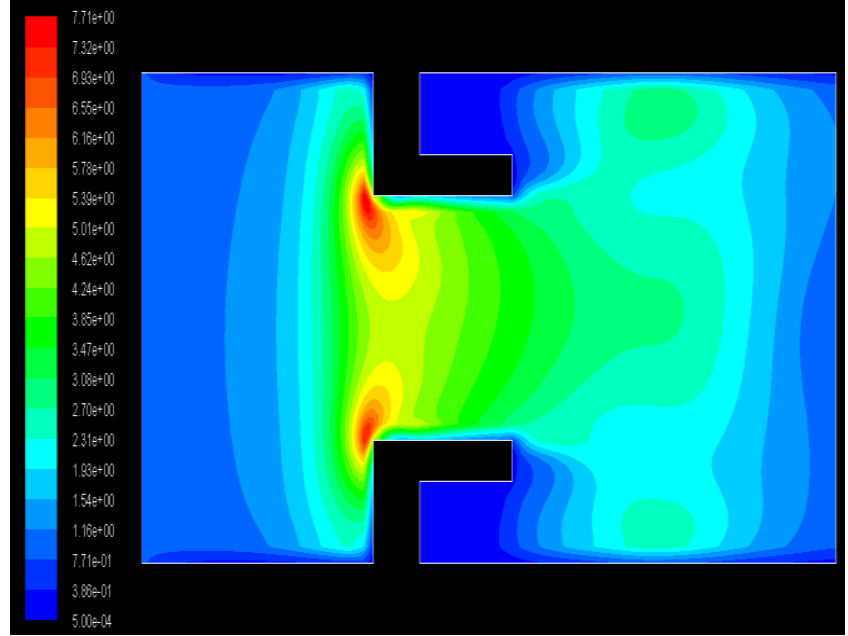

Fig- 5.2.3: Turbulent Contours.

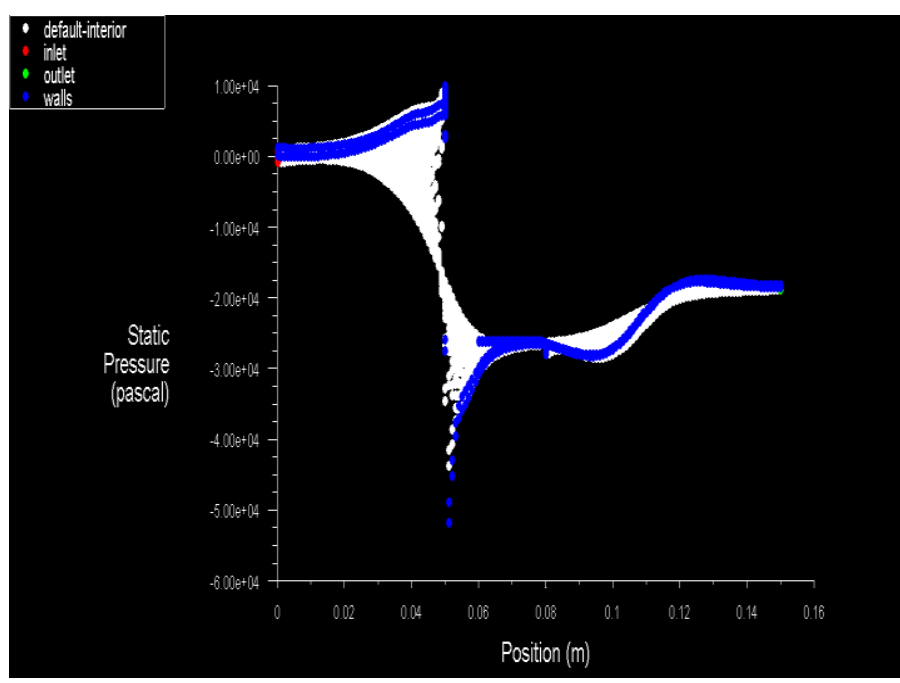

Chart-5.2.1: Pressure-Position.

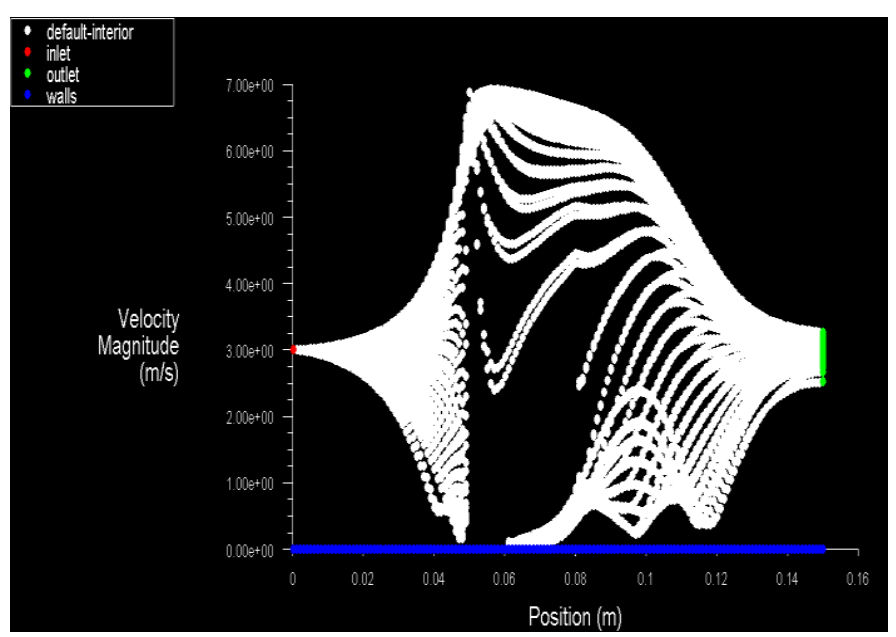

Chart-5.2.2: Velocity-Position.

Fig- 5.2.2: Velocity Contours. 


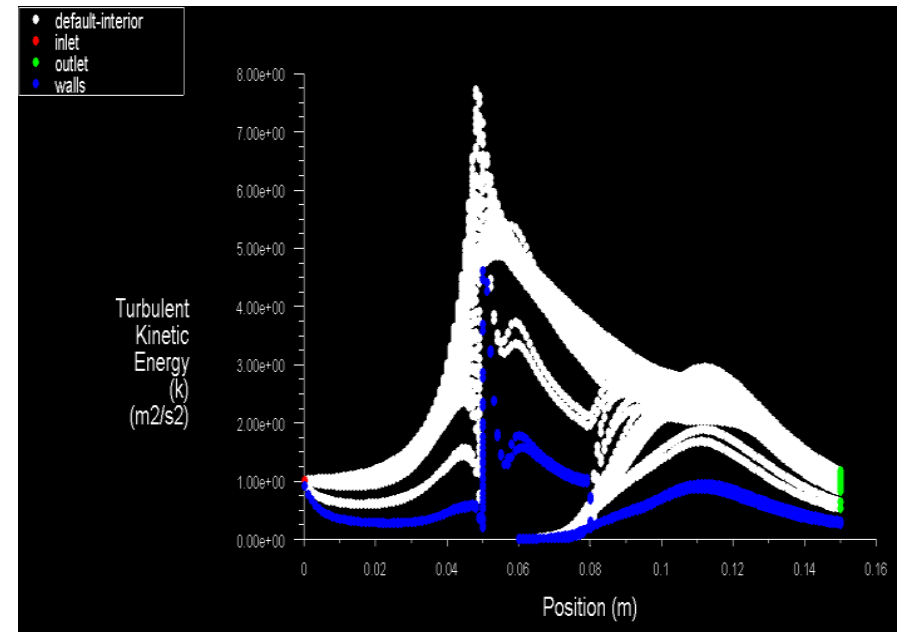

Chart-5.2.3: Turbulence-Position.

Table-5.2.1: results of flow analysis

\begin{tabular}{|c|c|c|c|}
\hline S.no & parameters & Min. & Max. \\
\hline 1 & Pressure $($ Pascal $)$ & -51817.77 & 9904.737 \\
\hline 2 & Velocity $(\mathrm{m} / \mathrm{s})$ & 0 & 6.918732 \\
\hline 3 & Turbulent $\left(\mathrm{m}^{2} / \mathrm{s}^{2}\right)$ & 0.00050 & 7.705388 \\
\hline
\end{tabular}

Table-5.2.2: results of mass flow rate.

\begin{tabular}{|c|c|}
\hline Mass Flow Rate & $\mathbf{( k g / s )}$ \\
\hline Interior & 1169.6085 \\
\hline Inlet & 179.67601 \\
\hline Outlet & -179.67601 \\
\hline Wall & 0 \\
\hline
\end{tabular}

\subsection{Results of Borda Type Flow Meter:}

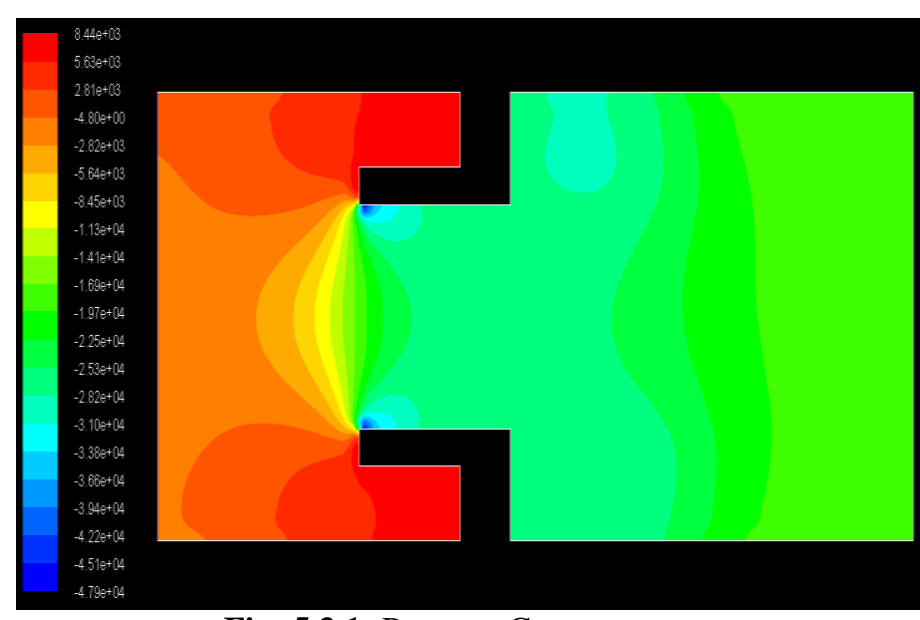

Fig- 5.3.1: Pressure Contours.

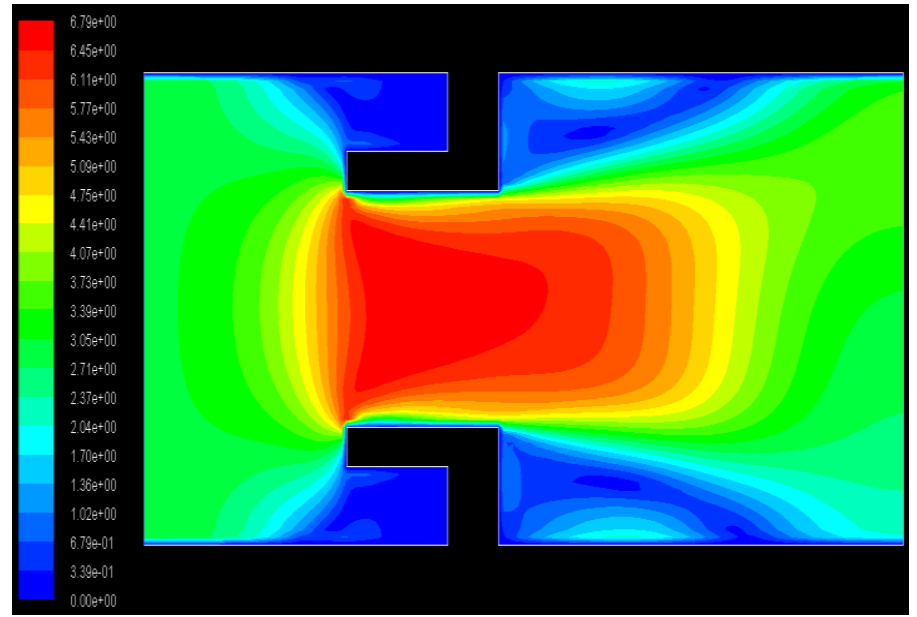

Fig- 5.3.2: Velocity Contours.

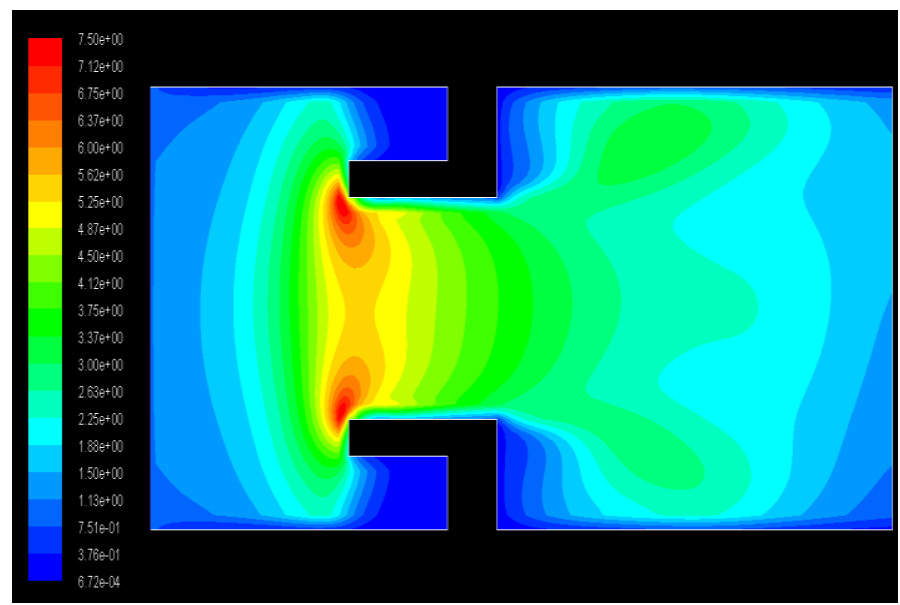

Fig- 5.3.3: Turbulent Contours.

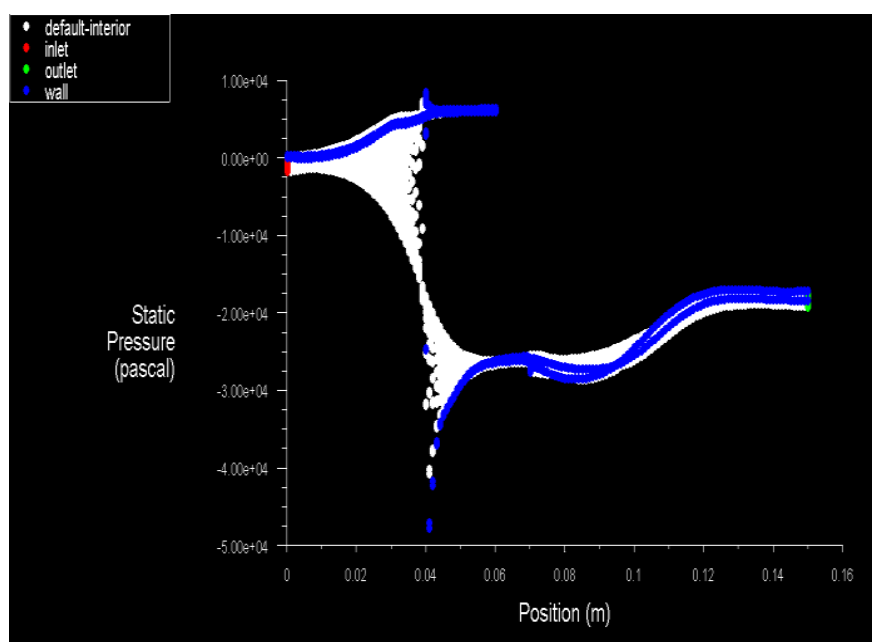

Chart-5.3.1: Pressure-Position. 


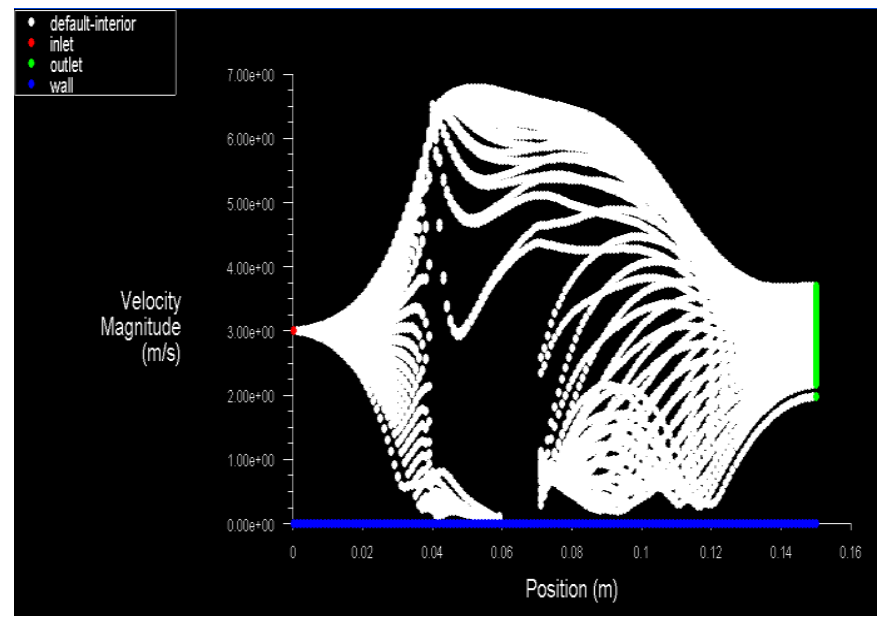

Chart-5.3.2: Velocity-Position.

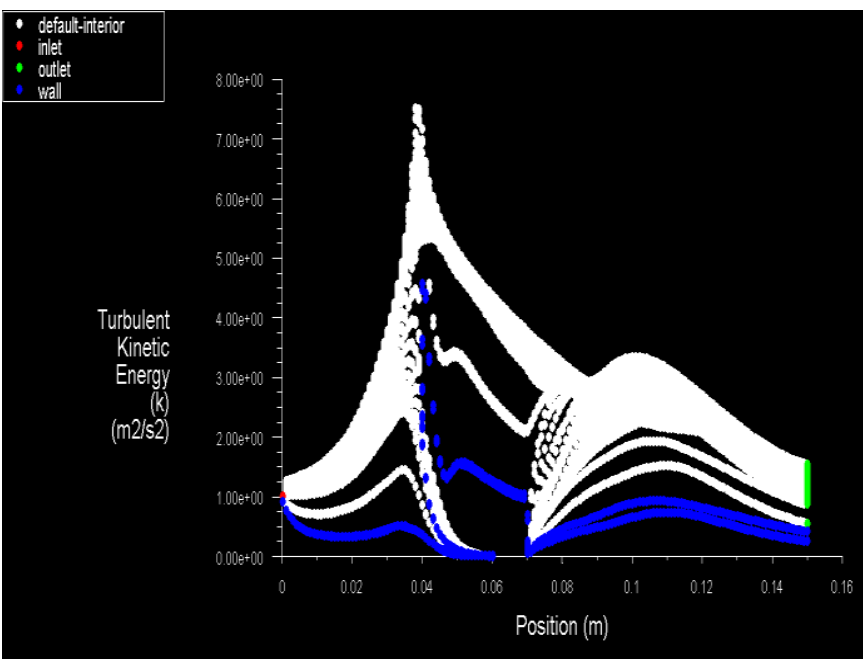

Chart-5.3.3: Turbulence-Position.

Table-5.3.1: results of flow analysis.

\begin{tabular}{|c|c|c|c|}
\hline S.no & parameters & Min. & Max. \\
\hline 1 & Pressure $($ Pascal $)$ & -47866.36 & 8441.355 \\
\hline 2 & Velocity $(\mathrm{m} / \mathrm{s})$ & 0 & 6.78514 \\
\hline 3 & Turbulent $\left(\mathrm{m}^{2} / \mathrm{s}^{2}\right)$ & 0.0006724 & 7.499114 \\
\hline
\end{tabular}

Table-5.3.2: results of mass flow rate.

\begin{tabular}{|c|c|}
\hline Mass Flow Rate & $(\mathbf{k g} / \mathbf{s})$ \\
\hline Interior & -2036.7402 \\
\hline Inlet & 179.67601 \\
\hline Outlet & -179.67601 \\
\hline Wall & 0 \\
\hline
\end{tabular}

\subsection{Results of Nozzle Type Flow Meter:}

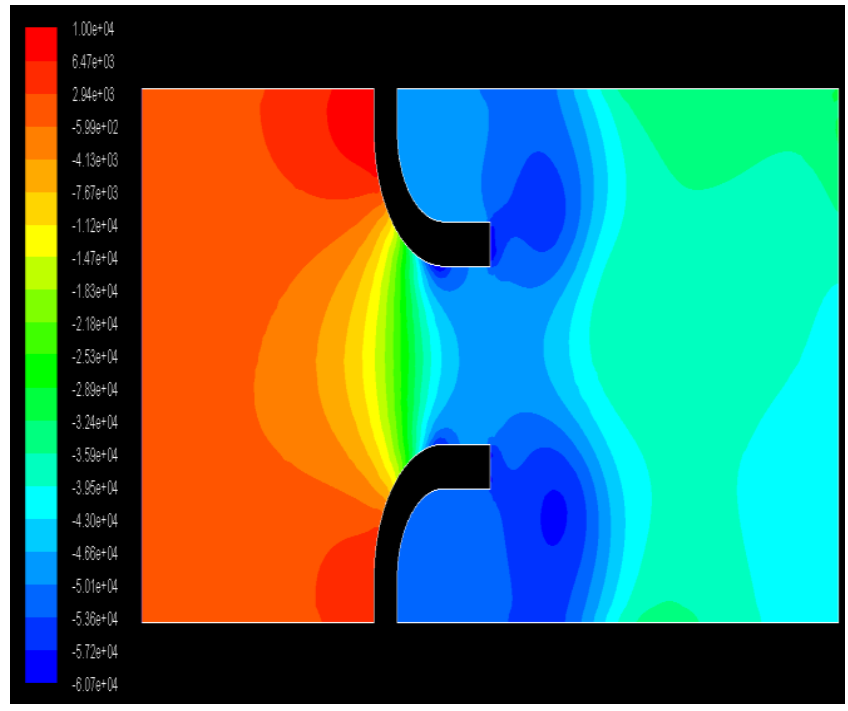

Fig- 5.4.1: Pressure Contours.

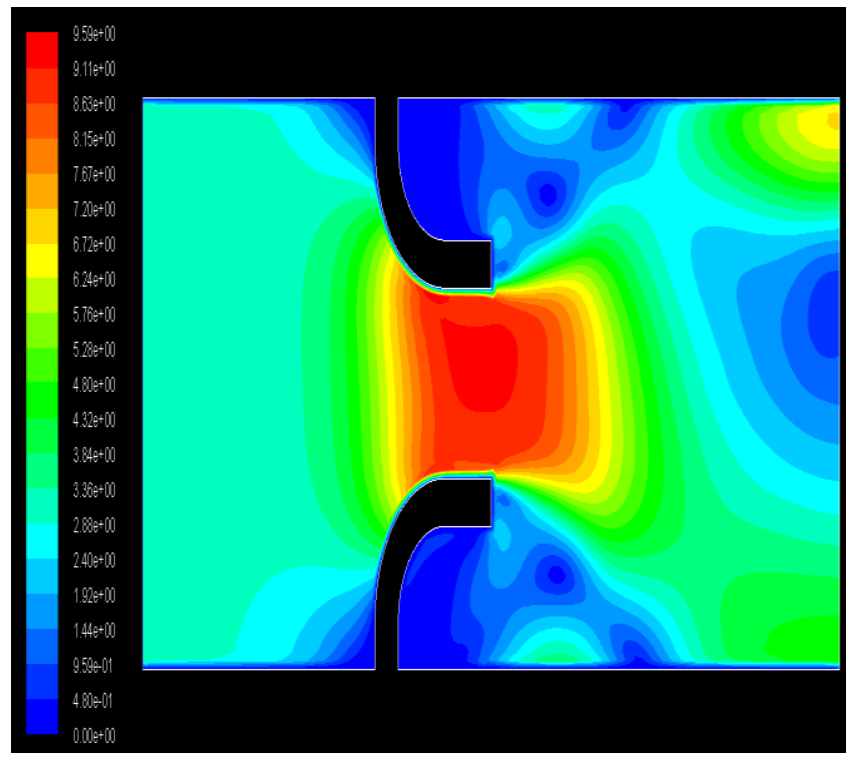

Fig- 5.4.2: Velocity Contours.

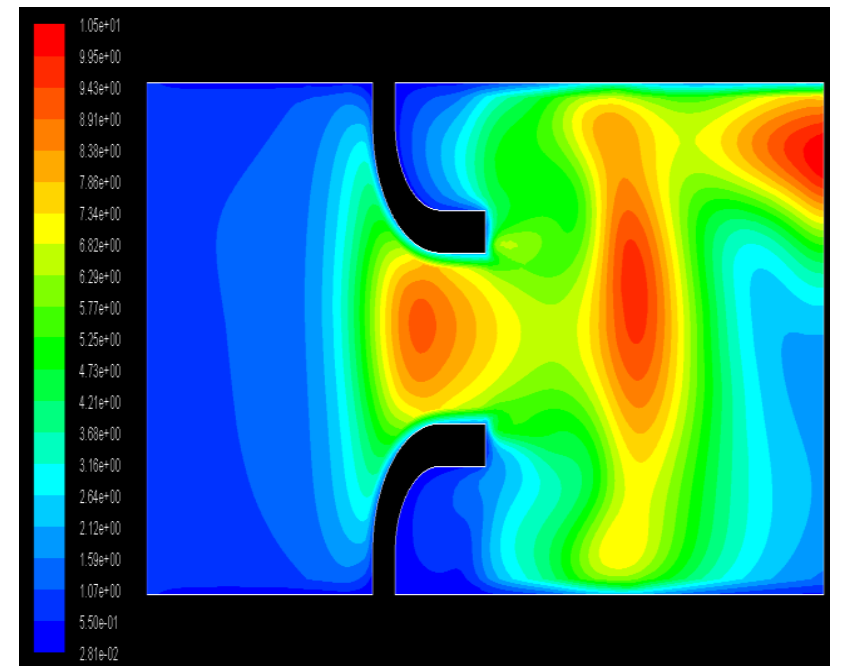

Fig- 5.4.3: Turbulent Contours. 


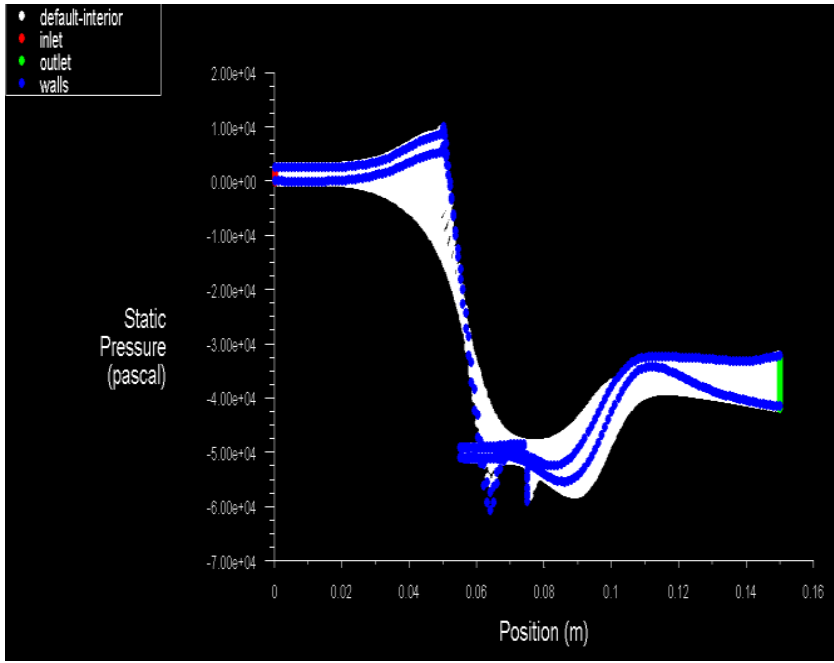

Chart-5.4.1: Pressure-Position.

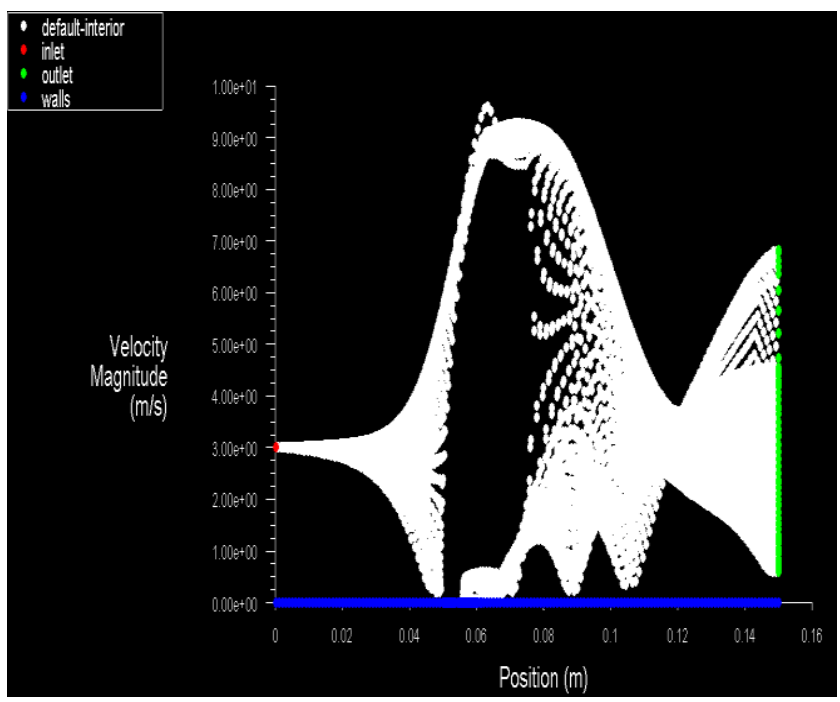

Chart-5.4.2: Velocity-Position.

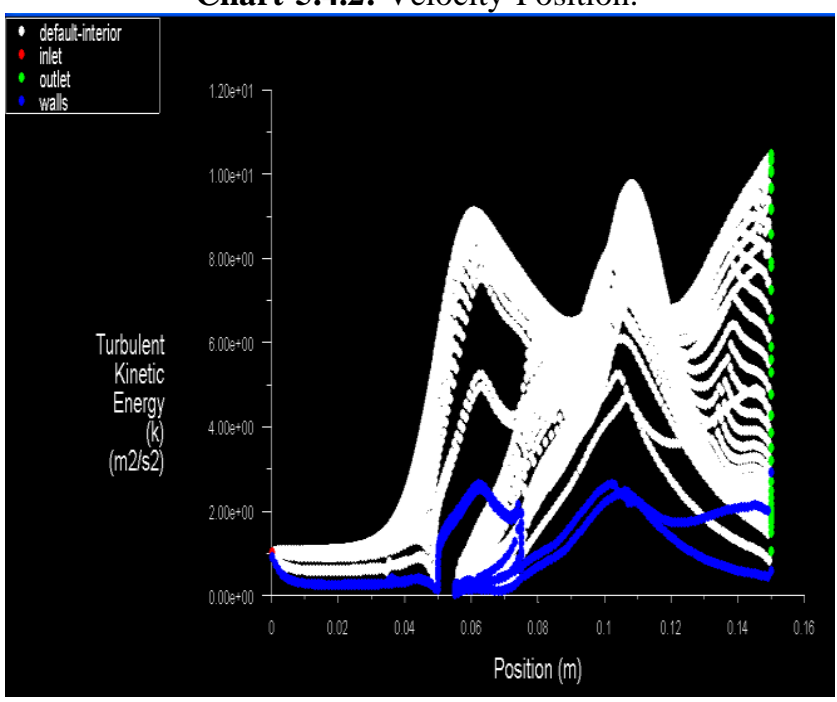

Chart-5.4.3: Turbulence-Position.

Table-5.4.1: results of flow analysis.

\begin{tabular}{|c|c|c|c|}
\hline S.no & parameters & Min. & Max. \\
\hline 1 & Pressure $($ Pascal $)$ & -60693.42 & 10006.32 \\
\hline 2 & Velocity $(\mathrm{m} / \mathrm{s})$ & 0 & 9.59358 \\
\hline
\end{tabular}

\begin{tabular}{|l|l|l|l|}
\hline 3 & Turbulent $\left(\mathrm{m}^{2} / \mathrm{s}^{2}\right)$ & 0.028088 & 10.4724 \\
\hline
\end{tabular}

Table-5.4.2: results of mass flow rate.

\begin{tabular}{|c|c|}
\hline Mass Flow Rate & $(\mathbf{k g} / \mathbf{s})$ \\
\hline Interior & 1209.1305 \\
\hline Inlet & 179.67601 \\
\hline Outlet & -179.67601 \\
\hline Wall & 0 \\
\hline
\end{tabular}

\section{CONCLUSIONS}

The flow pattern through an flow meter has been simulated for four different models, successfully, using CFD technique using fluent 6.3.26 solver. A good agreement between experimental data and CFD predictions flow patterns, pressure profile, velocity profile, turbulence model parameter and mass flow rate. It is also concluded that the CFD technique can be used as an alternative and cost effective tool to wards replacement requirement for estimating mass flow rate.

The design of a flow meter with a provision to track vena contracta using CFD technique has been explained. As per the application, selection of flow meters can be done and the behaviours of the flow pattern are plotted for four different models.

\section{REFERENCES}

[1]. Singh, Rajesh Kumar, Singh, S.N., Seshadri V.(2010). CFD prediction of the effects of the upstream elbow fittings on the performance of cone flowmeters. Flow measurements and instrumentation,21,88-97.

[2]. Patankar, S.V. and Spalding, D.B., 1972. "A calculation procedure for heat, mass and momentum transfer in three dimensional parabpara flows". International journal of heat and mass transfer, Vol. 15,pp. 1787-1806.

[3]. Singh, R.K., Singh, S,N. and Seshandri, V., 2010.'Performance evaluation of orifice plate assemblies under non-standard conditions using cfd". Indian Journal of Engineering And Materials Sciences, Vol.17, pp.397-406.

[4]. Seshadri , V., Singh, S.N., Pramod K.B., 2002. Performance Charateristics of Wedge Flow Meter using CFD, Journal of Computational Fluid Dynamics, vol.11,3,279-284.

[5]. Gerald., L. Morrison, Robert, E. D., Jr.Eric J.B.,1992. Installation Effect upon Flow meters, Journal of flow measurement and Instrumentation, Vol-3, No-2, 89-93.

[6]. Teyssedou A., onder E.N and Tye P.(2005) "Air-water counter-current slug flow data in vertical-to-horizontal pipe containing orifice type obstructions". International journal of multiphase Flow, 31,771-792.

[7]. Quinn W.R.”Experimental study of the near field and transition region of a free jet issuing from a sharp-edged elliptic plate". European journal of Mechanics B-Fluids.

[8]. Qing M., Jinghui Z.,yushan L., Quan D. (2006). Experimental studies of orifice-induced wall pressure Fluctuations and pipe vibration. International Journal of Pressure Vessels and piping. 
[9]. Turian R.M., Ma T-W., Hsu F-L.G and sung D.j.(1998). Flow of concentrated non Newtonian slurries:1.

Frictional loss through straight pipe. International journal of Multiphase flow, 24, 225-242.

\section{BIOGRAPHIES:}

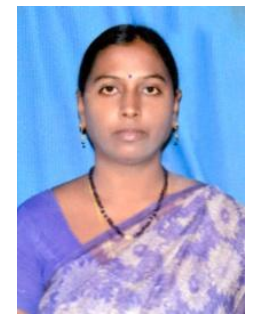

T.Sridevi completed schooling from St.Joseph's girls high school in guntur with $73 \%$ marks. Completed intermediate from Vidwan Junior College in Guntur with $75 \%$ marks. completed B.Tech Degree from J.N.T.U Campus.Hyd with $68 \%$. Now I am pursuing M.Tech from Kakinada Institute of Technology and Science,Tirupathi(V),Divili, East Godavari Dist, A.P, India.

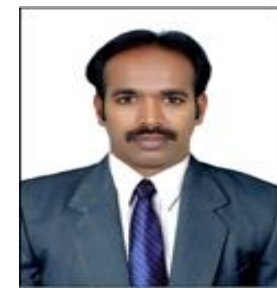

Mr. Y.Dhana Sekhar completed his B.Tech from A.S.R.College of Engineering and M.Tech from Godavari Institute of Technology \&Engineering, Rajahmundry. He has 2 years of Industrial and 2years of teaching experience. Now he is working as Asst. Professor and HOD of Mechanical Engineering in Kakinada Institute of Technology \& Science, Divili and doing research in Thermal Engineering.

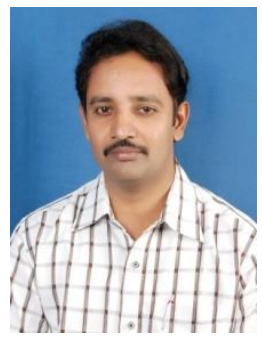

Mr. V.Subrahmanyam working as Assoc. Professor and Head of Mechanical Engineering Department in KITS-Divili Engineering college, Andhra Pradesh, India. He has 15 years of teaching experience in various reputed engineering colleges. He guided so many B.Tech and M.Tech projects. He has three publications in reputed international journals. $\mathrm{He}$ is doing research in NanoTechnology and Thermal Engineering. 